\begin{abstract}
In this paper I probe the kinds of views about selfhood that inform our understanding of sincerity and authenticity and argue that the terms have separate, but related, boundaries. Borrowing Frankfurt's notion of wholeheartedness, I argue that authenticity is a form of alignment or consistency within the self, which requires self-knowledge and intentionality in order to be actualized. Sincerity involves representing oneself truthfully to others but does not depend on the presence of authenticity. I contrast sincerity and authenticity in depth using literary examples. In the final section I call into question the assumptions underwriting the distinction between sincerity and authenticity and introduce the category of "shtick," which plays with both. I conclude that, although authenticity and sincerity stand in a complex relation to one another, that relation is neither one of synonymity, as might have been the case in the Renaissance, nor of sufficient condition, as Polonius famously claims.
\end{abstract}




\section{Refuting Polonius: Sincerity, Authenticity, and Shtick}

In a famous passage from Hamlet, Polonius gives his son Laertes the following sage piece of advice: 'This above all - to thine own self be true,/ And it must follow, as the night the day,/ Thou canst not then be false to any man' (Hamlet I.iii.78-80). Today, as in the Renaissance, truthfulness is highly valued both in self-regarding and other-regarding conduct. Self-regarding truthfulness of this kind is often described simply as authenticity, whereas otherregarding truthfulness goes by the name sincerity. What Polonius is saying, then, is that authenticity is a sufficient condition for sincerity. ${ }^{1}$ Four centuries of theatre-goers have nodded approvingly at his formulation. In this paper I want to challenge the assumed instrumental relationship expressed in Polonius's advice and to probe the kinds of views about selfhood that inform our understanding of both sincerity and authenticity. I hope to show that, while sincerity and authenticity are distinct and stand in no necessary causal relation to each other, a clean distinction is preserved only by adhering to a narrow version of selfhood.

In the first section I review Trilling's account of the origins of sincerity and authenticity in the modern era, drawing apart the two terms in their contemporary usage. Borrowing Frankfurt's notion of wholeheartedness, I argue that authenticity is a form of alignment or consistency within the self, which requires self-knowledge (or its pursuit) to be actualized. In the second section I confirm this hypothesis using a fictional example and conclude that authenticity furthermore must be intentional in order to be distinguished from coincidental selfalignment. Next I contrast authenticity and sincerity more closely, showing how they do not necessarily imply one another although they may share certain characteristics. In the final section I call the assumptions underwriting the distinction between sincerity and authenticity into question. Selfhood is not the type of thing that can be neatly known, represented, or hidden, as 
though it were a stagnant and fungible object. Instead, our 'true selves' are probably some combination of internal and external influences that we negotiate, part-consciously, partunconsciously, throughout our lives. While I reject Butler's radical thesis of performativity, I accept that our actual experiences of selfhood are more nuanced than the a priori binary between sincerity and authenticity implies. I conclude that, although authenticity and sincerity stand in a complex relation to one another, that relation is neither one of synonymity, as might have been the case in the Renaissance, nor of sufficient condition, as Polonius famously claims.

\section{What Lies Hidden}

In the last century, authenticity has frequently been a subject of philosophical examination - and excoriation - but the same is not true for sincerity. Most accounts of authenticity derive from the continental tradition, although the influential accounts of existentialist thinkers such as Heidegger and Sartre were heavily criticized by later philosophers

and, in the case of the former, associated with Heidegger's fascist politics. ${ }^{2}$ Moreover, sincerity is hardly considered in these accounts because of the existentialists' overriding concern with the self's way of being in the world and their idiosyncratic understanding of authenticity as an ontological (rather than ethical) project.

In more recent analytic literature, concepts that ring of authenticity and sincerity are fruitfully discussed by such authors as Bernard Williams, Harry Frankfurt and John Velleman under different monikers, presumably to escape some of the baggage associated with earlier scholarly debates, while related discussions about the parameters of the self continue among philosophers across traditions. Few contemporary philosophers, however, have reappropriated these exact terms and examined the dynamics of this intriguing dyad. Doing so may afford a 
sharper understanding of how the structure of the self-relation parallels, or does not parallel, our relations with others.

In a 1971 lecture entitled Sincerity and Authenticity Lionel Trilling examined some of the literary and social history of these concepts. In his text he is not particularly concerned with differentiating between and refining the parameters of each term, suggesting instead that they have similar meanings but prevailed in different linguistic settings. Trilling writes that 'before authenticity had come along to suggest the deficiencies of sincerity and to usurp its place in our esteem, sincerity stood high in the cultural firmament and had dominion over men's imagination of how they ought to be' (12). He attributes the former exaltation of sincerity in Western culture to a widespread concern about 'dissimulation, feigning, and pretence' in the Renaissance, citing as an example Polonius' well-known advice to Laertes (Trilling 13). Sincerity, as Polonius conceives it, seems to boast the twin virtues of preventing falsehood in one's dealings both with others and with oneself. In more recent vernacular, however, sincerity concerns avoiding deceiving others about oneself, whereas authenticity is judged on the absence of self-deception. ${ }^{3}$ It is the latter which occupies us to a much greater extent today, and which is both more interesting and challenging philosophically. Trilling concurs that our interest in the problem of deception has evolved since the $17^{\text {th }}$ Century:

The deception we best understand and most willingly give our attention to is that which a person works upon himself. Iago's avowed purpose of base duplicity does not hold for us the fascination that nineteenth-century audiences found in it; our liveliest curiosity is likely to be directed to the moral condition of Othello, to what lies hidden under his superbness, to what in him is masked by the heroic persona. Similarly Tartuffe, who 
consciously and avowedly dissembles, engages us less than the protagonist of $L e$ Misanthrope... (16)

So whereas sincerity was an urgent concern for audiences of the $16^{\text {th }}$ Century, Trilling argues that we are today more preoccupied with questions of authenticity. The villains of Shakespeare and Molière whose treachery is transparent to the audience may or may not have a truthful self-relation, but they are assuredly not sincere: they deliberately mis-portray themselves to others. The deception of others makes for engaging drama but its structure is elementary; there is no great confusion about what constitutes such insincerity. The same does not go for self-deception, or what has variously been called bad faith, inauthenticity, and lying to oneself. How can a person be false to, ignorant of, or misaligned with her own self? This is part of the conundrum of authenticity, and not necessarily demanded by questions of sincerity. While the terms may have been more porous in an earlier epoch, today sincerity is most accurately used to connote an interpersonal relation and authenticity an intrapersonal one. Metaphysically the latter is more vexing because it implies divisiveness or dissimulation within the self. If I am inauthentic, then the person that I am is somehow false to the person that I ought to be, or to the person that I 'really' am, 'underneath it all.' The twin concepts of authenticity and inauthenticity thus challenge the structure of the self as a unit that is by definition self-coincident. Insincerity presents no such metaphysical challenge because we are not accustomed to thinking of the self and the impression others have of it as necessarily coincident. ${ }^{4}$

While I do not propose to provide a complete account of authenticity in the present paper, it will be useful to have a greater understanding of how the self-other relation known as sincerity can be replicated or mimicked within the same person. A salutary theory is furnished by Harry Frankfurt. In his essay 'Identity and Wholeheartedness' he asks what makes a person's desires 
consistent, or wholehearted, such that we can say they issue genuinely from that person's self. Because authenticity is a question of grasping what we call the true self, and because desires ${ }^{5}$ are indicative at least in some way of the self whence they arise, we can think about authenticity in terms of Frankfurt's wholeheartedness.

Frankfurt identifies several types of desires, which are worth clarifying before analyzing his argument. He designates the desire that actually leads to action as the will. In addition to this 'effective' desire, we may have numerous other desires that do not ultimately get acted upon, but are still of the first order. ${ }^{6}$ Further, he says, 'people characteristically have second-order desires concerning what first-order desires they want, and they have second-order volitions concerning which first-order desire they want to be their will.' (Frankfurt 1988: 164) The conflict that interests Frankfurt most - the one that admits of the presence or absence of what he calls 'wholeheartedness' - is that between our second-order volitions concerning our will. What happens when we don't actually know what we want to be our will? He poses this question in terms of identification with one's motives. If we fail to fully identify with some of our motives, we cannot legitimately portray ourselves as being constituted by them, just as we mask our true constitution when being insincere to others. Wholeheartedness does not require absolute consistency among our desires, but only that we identify with one consistent set of desires that we want to be our will, and repudiate others. It is a question of assimilating some desires as belonging to us and regarding others as foreign. ${ }^{7}$

It is crucial to note that Frankfurt's concern with identification has higher stakes than just the metaphysical clarity it seeks to achieve. According to Frankfurt, we 'constitute ourselves' by identifying with certain volitions and not others (1988: 170). To act upon those volitions with which we identify is therefore an act of fidelity to the self. Although he does not use the 
vocabulary of authenticity, Frankfurt is here addressing the same concerns about what it means to be 'true to oneself.' Wholeheartedness is the condition of thoroughly identifying with one's first-order desire or motive as well as all the higher-order ones implied by it, so that the resulting action can be said to issue from a single, harmonious self. The consistency of the will expressed in wholeheartedness evokes the 'true self' that we associate with authenticity. Meanwhile, the lack of wholeheartedness is obviously akin to a state of inauthenticity, as Frankfurt explains: 'In the absence of wholeheartedness, the person is not merely in conflict with forces 'outside him'; rather, he himself is divided' (1988: 165). This internal divisiveness speaks to the same undesirable inconsistency that we associate with bad faith or lying to oneself. Wholeheartedness thus has the same logic and lure as authenticity.

This is not to suggest that wholeheartedness and authenticity are coextensive but as a sketch of truthfulness to oneself the comparison will serve us well. ${ }^{8}$ We can now understand how the problem of insincerity finds expression not only in my interactions with others, but also within my own mind. I may be wholehearted, or I may be genuinely confused or undecided as to what I most identify with. If the latter is the case, I maintain an insincere-like relation to some parts of myself. When acting on desires that are not wholehearted, I am in some sense being false to those desires I have with which they are inconsistent. It should be evident that sincerity, unlike authenticity, does not require wholeheartedness. I can be honest with others regardless of whether I am wholehearted or not.

Frankfurt's wholeheartedness is also useful in this context because it signals other features of the authentic self-relation that might help us to distinguish it from the others-relation. It is clear, for instance, that if I am to bring all my motives into a consistent volitional set, I require at the very least a good knowledge and understanding of my motives. In other words, 
self-knowledge is also a requirement of authenticity as long as wholeheartedness is. ${ }^{9}$ Is such selfknowledge required for sincerity? I will explore this by means of a fictional example.

\section{Precisely Aligned With Oneself}

Forrest Gump exemplifies a life that is breathtakingly diverse but painfully lacking in depth because of the character's unusually low intelligence. The character drifts through unplanned careers (shrimp-fishing, ping-pong playing, long-distance running) and historical milieus (Vietnam and the Cold War, the civil rights movement, the beginning of the AIDS epidemic) utterly oblivious to his role in history, inadvertently starting trends and effecting changes that the audience recognizes as major twentieth century cultural and political phenomena. Because of his inability to reflect on, analyze, or assimilate any of his experiences, Gump literally floats through phases of life that are burgeoning with historical and psychological significance and fails to draw any instructive connections between them. He is unable to understand his motives and hence incapable of identifying with or repudiating any of them as Frankfurt requires. This function is completed by the audience. ${ }^{10}$

We can say that Gump lacks self-knowledge, but not that he lacks sincerity. Indeed, his charm is contained in this vulnerable combination of self-ignorance and truthfulness in his dealings with others. Gump answers questions as honestly and forthrightly as possible (often with embarrassing results); he is utterly transparent. Gump announces no commitment to the ideal of sincerity - even this would exceed his limited cognitive capacities - but his behaviour is honest almost by definition. Because he lacks self-knowledge, however, authenticity as we have defined it eludes him. It would seem, then, that Gump is the paradigm of sincerity without authenticity. 
Perhaps this conclusion is too hasty. It depends on the assumption that one cannot be true to anything without knowing what it is to which one is being true - thus his ignorance of his own motives means that Gump cannot be authentic. But is this naïve character not indeed consummately, compulsively himself in view of that very absence of self-knowledge? There appear to be no layers to his personality; he suffers from no internal tension. Everything he does strikes us as innocent, undiluted Gump. As Trilling says, to be true to oneself means, 'as carpenters and bricklayers use the word, [to be] precisely aligned with him' (4). Was there ever a person more precisely aligned with himself than Forrest Gump?

I may be mistaken in my assumption that Gump is free of conflict and therefore not in need of self-examination - or even if he is, this might be a situation obtainable only in literature, not in real life. It is difficult to imagine that any real person is so one-dimensional as to possess complete self-knowledge without effort. As Frankfurt argues, any particular motive we have is very likely to be inconsistent with at least one other, and reconciling them tends to require conscientious psychological work. This work is precisely part of what we value in the authentic individual. Unwavering sincerity with respect to others, such as Gump displays, is not sufficient for authenticity; internal wholeheartedness is also required, and that demands an intimate confrontation with conflicting layers of one's self. ${ }^{11}$ So a person who lacks hard-earned selfknowledge cannot be authentic, even if she is sincere. Moreover, even if Gump is free of internal conflict (that is, if he is wholehearted in Frankfurt's terminology), that this is due to simplicity rather than acts of reconciliation removes him from contention for authenticity.

Another reason we balk at counting someone as simplistic as Gump in the ranks of the authentic is because his actions, however 'true to himself' they happen to be, achieve that status at best coincidentally, not intentionally. This is a direct result of his lack of self-knowledge or 
complexity. Gump does not set out to behave in a manner consistent with his most constitutive motives at the expense of ones he finds more foreign. Such intentionality ${ }^{12}$ would of course be impossible since he lacks any critical distance from those motives. If he chooses actions that happily coincide with some essential self, the overlap is fortuitous. By contrast, we tend to think of the authentic person as making deliberate choices about how to live her life. Tremendous changes in life direction should issue from a conscious change in motives, not merely contingent changes in circumstances, as they do in Gump's life. ${ }^{13}$ For instance, a person who chooses to leave a lucrative career in finance in order to pursue a dream of writing fiction strikes us as more authentic, ceteris paribus, than a bored finance executive who happens to receive a book deal. This is on the assumption that the authentic person determined her inner writer to be more constitutive of her real identity than the career she was in, and chose to rearrange her life accordingly. Hence, as indicated by the criterion of wholeheartedness, authenticity seems to entail self-knowledge and intentionality, both of which Gump lacks.

Nonetheless, we might not want to say that Gump is positively inauthentic. While inauthenticity may be distinguished by the absence of self-knowledge, it could be said to share with authenticity the trait of intentionality. If authenticity does not happen by accident, perhaps neither does inauthenticity. For instance, if the aforementioned finance executive were to recognize and identify with her desire to be a fiction writer, but nonetheless persist in a career that made her feel dissatisfied or uncomfortable, we would call her inauthentic. One who is simply ignorant about himself, such as Gump, may be neither authentic nor inauthentic. This in turn will have implications for sincerity. I will return to this problem shortly.

\section{May One Be Pardoned and Retain th'Offence?}


In order to further test the hypothesis about the distinction between authenticity and sincerity, let us consider a person who is the opposite of Gump: wholehearted, selfknowledgeable and acting intentionally, but insincerely. An example is furnished by another character from Hamlet. The murderous king Claudius lives insincerely by enjoying the rewards of his crime while everyone believes his predecessor to have died of natural causes. He lies to everybody - except to himself. Indeed, Claudius shows himself to be evil to a disturbingly thorough degree by virtue of this internal consistency:

My fault is past - but $\mathrm{O}$, what form of prayer

Can serve my turn? 'Forgive me my foul murder'?

That cannot be since I am still possessed

Of those effects for which I did the murder -

My crown, mine own ambition, and my queen.

May one be pardoned and retain th'offence? (Hamlet III.iii.51-55, 97-98)

As Frankfurt requires, Claudius chooses to identify with one consistent set of desires at the expense of another. He is unwilling to identify with his desire for remorse because he understands that it would logically deprive him of the consequences of his other desires, to which he still clings. ${ }^{14}$ Hence his attempts at prayer are hollow: he has expunged his desires for forgiveness from the consistent set of desires with which he identifies. While his priorities are reprehensible, his reasoning is remarkably lucid. On the criteria of wholeheartedness, selfknowledge, and intentionality, the masterful liar Claudius is in fact authentic. ${ }^{15}$

Polonius' advice to his son about the causal relationship between self-truthfulness and truthfulness to others is thus belied by his own friend. ${ }^{16}$ This example shows that 
authenticity does not imply sincerity. Claudius can be true to his own self while being false to every other man.

Can Claudius' situation be reversed? Can one be true to others while being false to oneself? This was not sufficiently answered in the Gump example because, as we saw, he is neither obviously inauthentic nor authentic.

If one could be sincere yet inauthentic, this would take the form of being true to others while being false to oneself. This is incoherent, except insofar as a person is ignorant of or mistaken about who she really is. If self-knowledge is possible, however, self-ignorance must be as well. Both conditions exist in some sense as long as there are any verifiable facts or characteristics about the self. In principle a person could genuinely believe herself to be one way, and lead others to believe she is that way, when in fact she is very different. ${ }^{17}$

This exposes a new element of sincerity: sincerity entails representing oneself to others as one actually understands oneself. If I understand my motives to be $\mathrm{X}, \mathrm{Y}$, and $\mathrm{Z}$, then I am sincere insofar as I lead others to believe that my motives are $\mathrm{X}, \mathrm{Y}$, and $\mathrm{Z}$ - even if my motives are actually A, B and C. I could then, at least theoretically, be sincere and inauthentic. For instance, Tom may go to visit his grandmother believing that his motive is to raise her spirits, and accordingly lead his parents and her caregivers to believe the same thing. In actual fact, he visits her because she always gives him his favourite foods; if she did not, he would stop visiting her. But Tom is not aware of this underlying, less praiseworthy motive for visiting his grandmother. He sincerely believes that his motive is selfless, but insofar as he is mistaken about this, his sincerity also indicates an absence of authenticity.

With Gump it is impossible to say for certain whether he is mistaken about his real motives, or correct but incredibly shallow, as suggested by his paper-thin character. Either way, 
his sincerity does not depend on any deep self-knowledge. He represents himself exclusively as he understands himself, however superficial that understanding is. This shows that sincerity can be a trivial virtue and perhaps not worth caring much about. I will call this the thin account of sincerity. We might prefer a more rigorous criterion of sincerity that includes 'correct' selfknowledge as well as non-dissimulation to others. To be sincere on this version requires more than showing people who one thinks one is; it requires showing others who one 'actually' is. ${ }^{18}$ On this thicker account of sincerity, Gump might cease to be sincere as well as authentic. Without accurate self-knowledge, one might neither be true to oneself nor meaningfully true to others. ${ }^{19}$

Rousseau's character Julie is also sincere but her authenticity is highly questionable. In Julie ou la Nouvelle Heloïse, after years of a passionate love affair with St. Preux, the young woman reluctantly goes along with her father's plan to marry her to an older man for whom she has no feelings. In a letter to her former lover after the marriage, she describes the unexpected transformation that overtook her in the church: 'It was as if an unknown power repaired all at once the disorder of my affections and re-established them in accordance with the law of duty and nature' (Rousseau 292). Thenceforth, Julie claims to be happy in her virtuous marriage to Wolmar and tells St. Preux that 'Julie de Wolmar is no longer your former Julie' (Rousseau 299). Nonetheless, they continue to correspond and even have a private reunion on the grounds of her husband's estate. As Williams notes, there are 'layered ambiguities that surround Julie's passion for her lover' and the content of their letters 'leave it compellingly indeterminate how her feelings are to be described' (183). It is certainly questionable whether she is being true to herself, and if so, what that truthfulness consists in: did she indeed experience a change of heart about St. Preux? Did she successfully suppress her passion by identifying (as Frankfurt might 
require) more strongly with her sense of virtue? Readers can only speculate. What is clear is that Julie's authenticity or lack thereof has no impact on her capacity for sincerity. She continues to pour her heart out in epistolary format throughout the emotional twists and turns of her story, and as far as we know her disclosures are genuine. ${ }^{20}$

\section{Playing with Being}

We have contrasted sincerity and authenticity in a number of ways and begun to ascribe some minimal criteria to each. Sincerity is an interpersonal disposition, which consists in representing oneself to others as one understands oneself, or, more robustly, as one in fact is. Authenticity is an intrapersonal disposition that requires (but is not necessarily reducible to) wholeheartedness, self-knowledge and intentionality. In principle it seems that one can be sincere without being authentic and vice versa. In this final section I will problematize these tentative conclusions by interrogating the beliefs about selfhood on which they depend.

Sharp divisions between 'who I am' and 'what I tell others I am' depend on a narrow view of behaviour and identity. Specifically, they require that I have some ready-made, independent identity, and that it be immune to influence by social interactions or cultural meanings. Only then can I choose to present my identity to others strictly sincerely or insincerely. Many philosophers, especially in the feminist and postmodern traditions, would be skeptical of such premises, and consequently of the distinction between authenticity and sincerity - and with good reason. Because we live in a social world permeated with behavioural norms, our identity often contains a performative or dialogical element that blurs the lines between the 'true' self and the self that is presented to others. Moreover, the assumption that we have at any given moment a single, true identity, which can be either simply reflected or denied in our 
conduct, assumes a level of metaphysical essentialism and stagnancy in personal identity that is counterintuitive. $^{21}$

One of the most radical theses about the overlap between personal identity and social performance is championed by Judith Butler. In Gender Trouble, Butler argues for the notion of performativity in her analysis of gender identity. ${ }^{22}$ Claiming that gender is not a natural category, but culturally coded through gestures and signs, she concludes that we cannot speak of a 'true' gender identity that undergirds an individual's gender performance. The notion of such a pre-existing identity, she says, is illusory:

Acts, gestures, and desire produce the effect of an internal core or substance ... Such acts, gestures, enactments, generally construed, are performative in the sense that the essence or identity they purport to express are fabrications manufactured and sustained through corporeal signs and other discursive means. That the gendered body is performative suggests that it has no ontological status apart from the various acts which constitute its reality. (Butler 173)

Butler contrasts performativity with expressiveness, which refers to the presentation of a preexisting identity such as we have been assuming to be possible in discussions of sincerity: 'If gender attributes, however, are not expressive but performative, then these attributes effectively constitute the identity they are said to express or reveal. The distinction between expression and performativeness is crucial' (180). If gender attributes are performative, Butler continues, there are 'no true or false, real or distorted acts of gender, and the postulation of a true gender identity would be revealed as a regulatory fiction' (180). In the case of gender identity, if not other aspects of identity as well, Butler believes that simple expression ${ }^{23}$ is not possible. 
In pulling the ontological rug out from under the notion of gender identity, Butler forecloses the possibility of a distinction between sincerity and authenticity with respect to gender. I cannot be insincere about my gender identity in my conduct since it is that conduct alone that amounts to my gender identity; sincerity, understood as the expression of an internal state, is impossible. Even more concerning for this discussion, Butler's theory of gender is hostile to the structure of authenticity as such. If there is no identity (gender or otherwise) separate from its social performance or construction, it becomes nonsensical to talk about the convergence between one's identity or true self and one's behaviour. Her skepticism of the metaphysics of substance calls into question the very intuition that something persists under the manifold behaviours that we attribute over time to a single identity. She claims that ' $[0]$ ntology is ... not a foundation, but a normative injunction that operates insidiously by installing itself into political discourse as its necessary ground' (Butler 189).

Butler is arguing not that identity is socially conditioned, or that we must distinguish between genuine identity and adopted artifice, but something much more severe: she is claiming that there is no such thing as identity in the normal sense of the word, at least when it comes to gender. The genders by which people 'identify themselves' - as feminine, masculine, or some combination thereof - have no correlate in the individual's inner constitution. Hence it is nonsensical to speak of either sincerity or authenticity in this respect.

I do not find this view of identity as entirely contingent to be plausible, not only because it renders questions of authenticity moot, but moreover because it fails to account for what, in the end, determines the gender that we peform. I readily grant that gender is probably not innate or even meaningful outside of carefully circumscribed social rules, but there is nonetheless a source of our determinations about gender, which allows for gender 'identities'. As long as individuals 
identify with something - in the sense of, for instance, feeling comfortable wearing certain clothes and wanting to be referred to by certain pronouns - some information about a person is being given. No doubt the information is a product of the interaction between oneself and external pressures, but there is an 'I' that chooses at some point to make that identification. Butler might respond that in our heterosexist gender-polarized culture, any choice to identify otherwise is illusory. Be that as it may, there is some basis upon which individuals come to identify with a gender or with any other social role and not with others. That basis must be, in the final analysis, something that we can call the individual's identity. Regardless of whether we conceive of the self as an essential core or as an unhinged collection of choices, to accept that people identify with certain roles and not others invites Frankfurt's line of questioning: perhaps the role itself is not essential to me, but what about the motive to identify with the role, or the motive to have that motive, and so on? Something about $m e$ - however elusive - will eventually intervene in the chain to account for how I identify myself.

Hence, despite Butler's radical thesis, performativity is not a serious challenge to my account of authenticity and sincerity. Although our choices of identification are limited and sometimes prescribed without our consent, we forge an identity on the basis of some internal response to our circumstances. That internal response - whatever its origin - is a signal of identity, one that can be addressed with varying degrees of authenticity and sincerity. We can 'perform' gender without sacrificing the intuition that gender picks up aspects of our true selves.

The solution to the more moderate concern about the fluidity of selfhood is not to reject any theory of sincerity and authenticity outright, but to modify the essentialist account of the self implied by them. For instance, it is possible to acknowledge that one experiences and expresses identity in plural and open-ended ways without thereby concluding that she has no 'real' identity. 
We do not approach social situations as stagnant, ready-made selves. The self is formed, at least in part, through interactions with others. ${ }^{24}$ Williams urges that

we must leave behind the assumption that we first and immediately have a transparent self-understanding, and then go on either to give other people a sincere revelation of our belief ... or else dissimulate in a way that will mislead them ... we are all together in the social activity of mutually stabilizing our declarations and moods and impulses into becoming such things as beliefs and relatively steady attitudes. ${ }^{25}$ (193)

It follows from Williams' lucid analysis that the prospect of being sincere is less straightforward than simply telling the truth about oneself, since the self is not a dissociated object of interpretation. To the extent that my identity evolves along with my self-revelation to others, it may seem superfluous to distinguish between authenticity and sincerity; authenticity is simply not a project I can pursue in isolation from others. The same material of experience leads to both others' beliefs about me and my own beliefs about myself, and the two sets of beliefs then iteratively and, often, unconsciously inform one another. Thus we can see how Polonius, ahead of his time, might have come to the conclusion that authenticity is somehow causally bound up with sincerity. However, Polonius' interpretation of this relationship is flawed: he assumes that one's authentic self-relation is a pre-cursor to sincerity, instead of a parallel emerging practice.

Sincerity and authenticity can plausibly be understood as intertwined endeavours, both issuing from an ongoing exploration of one's identity in a social milieu. At the same time, sincerity and authenticity are not fully interchangeable. Consider the notion of role-playing, which can be viewed, as in the Renaissance literature Trilling reviews, as a type of dissimulation. Molière's Tartuffe is obviously role-playing: he pretends to be a pious clergyman while 
revealing his impiety to the audience. But not all public personas are such clear-cut examples of insincerity. ${ }^{26}$ We behave differently among different people, drawing from a repertoire of identities to suit the situation - sometimes the pious man, sometimes the thinker, sometimes the flirt. We readily describe ourselves 'in the role of' mother, student, Canadian, and so on, without compromising the legitimacy of any of them. Roles are not masks intended to disguise who we are, but are the very content of who we are. Moreover, roles assume meaning only in a social context and we may experience them as thrust upon us - along with attendant assumptions and associations - rather than freely chosen. Whereas early Moderns might have disparagingly characterized such social roles as pretence, post-moderns are more likely to describe them as evidence of the versatile and multilayered nature of identity. The effect might be to stretch the category of the sincere: we can tell the truth about ourselves in many situations, but perhaps without telling the whole truth. The side of me that is known to work colleagues is not an inaccurate depiction of who I am, but it may lack the depth of the picture that is known to my oldest friends.

An appreciation of how identity is made up of roles is not tantamount to sanctioning any role whatsoever. We can still identify - and condemn - genuine pretence and outright lying; not all roles are de facto sincere. Embodying roles, one or more at a time, is consistent with the possibility of both sincerity and authenticity as long as we understand that some roles are truthfully played and others not. We would not say, even on a revised theory of the self, that Tartuffe is sincere because he plays the role of a priest. He is not, by any standard, a priest. ${ }^{27}$ Nor would we say that he is sincere because hypocrisy and opportunism are feelings he genuinely experiences. Pretending to be something you are not is insincere by definition. His is an easy case. ${ }^{28}$ 
A tougher case is seen in a situation of minor exaggeration of an identity that is genuinely held. Recall Sartre's example of the waiter. Sartre judges that the waiter is in bad faith - that is, inauthentic - based on his movements. This individual, on Sartre's observation, throws himself into his job, over-accentuating the characteristics he most associates with being a waiter, precisely in order to flee the nothingness that separates him from his profession - that is, to flee his freedom to not be a waiter. ${ }^{29}$ As Sartre says, 'he is playing at being a waiter in a café. ... the waiter ... plays with his condition in order to realize it' (102). Hence there is something obviously feigned, or forced, about his being in this situation. The artifice is a deliberate attempt to mask an unsettling truth: the waiter's ability to transcend his situation.

Against Sartre, I believe that the waiter's authenticity is something we are not in a position to judge, since we lack knowledge of his interior constitution, but we might agree that the waiter appears to be less than fully sincere. He is a waiter, but if Sartre is to be believed, he is trying too hard at fulfilling that role. He is too quick, too attentive, too self-conscious. He is possibly caricaturing his mental image of the ideal waiter. None of this means that he is lying about being a waiter, but perhaps there is a discrepancy between the degree to which he is acting as a waiter and the degree to which he actually is a waiter. His actions do not simply state, 'I am a waiter,' but rather scream, 'I AM A WAITER!' If he were more sincere, he might perform his café duties less conspicuously. He is not pretending to be something he's not, but he might be pretending to be it to an exaggerated degree. Indeed, this pretense may be for his own benefit as much as others'. ${ }^{30}$

Many people experience this intentional, albeit slight, variation on sincerity. We often play up aspects of our identity on purpose in order to achieve a particular persona, playing with both authenticity and sincerity simultaneously. We have what can be called a shtick. Imagine 
that my athletic ineptitude is well-known. I may come to define myself in part by this deficiency and even exaggerate it for the amusement it provides. Being bad at sports is my shtick. So when, at a picnic with friends, a Frisbee comes in my direction, I feign terror and block my face with my hands. I might have been able to catch it, but in a split-second evaluation I reason that it would be funnier to not even try. I have little facility with disc-catching, but I know that a softly sailing piece of rubber will not actually hurt me, and the terror reaction is excessive. I am quasisincere: I play up my athletic ineptitude on purpose, exaggerating the role that I sincerely inhabit. Being mostly poor at sports is not especially amusing. Being afraid of harmless sports equipment has comic potential.

I am in this situation both sincere and insincere, authentic and inauthentic. It is true that I am generally unable to catch Frisbees, and I am comfortable revealing this to my friends. However, by exaggerating this trait to the point that I no longer even try to catch Frisbees, I am simultaneously revealing and concealing my true abilities, being who I am and being a little bit more than that at the same time. I am sacrificing a certain measure of sincerity and authenticity for the sake of something else, which might be a more constitutive part of my identity, and hence sincere or authentic in its own right - the desire to amuse his friends, for example, or to cultivate trademark characteristics in order to achieve certain social ends. Such trade-offs are commonplace and attest to the interconnection between authenticity and sincerity. We choose how to behave, and consequently how much of our true selves to heed, partly in consideration of how we want to present ourselves to others. I am not only revealing certain parts of my identity, but also, as Williams explains, actively constituting myself as a person who is hopeless at sports. The next time I cower from a flying disc my behaviour might be more fully sincere, because this is indeed how I have come to regard myself. 


\section{Conclusion}

The concept of authenticity, both in its early modern and more current instantiations, implicitly assumes the existence of a true self that can either be accurately manifested or betrayed in our dealings with ourselves. Likewise, sincerity assumes that we have a good understanding of this self, that it is relatively robust in the face of external influences, and that we may choose to portray it accurately or hide it from others. These are both compelling ideas with a long history in Western thought and civilization.

I have attempted to clarify both sincerity and authenticity by showing how they do and do not overlap and forwarding criteria for the understanding of each. In the case of authenticity, Frankfurt's notion of wholeheartedness is a useful way of explaining the possibility of dissimulation within the self as it sometimes occurs in relations with others. Authenticity that begins with wholeheartedness requires, at a minimum, self-knowledge and intentionality. Selfknowledge is a problematic indicator because of its assumption of the objectivity of selfhood, but in many cases we can be aware or ignorant of our true motives and desires. The distinction between 'thin' and 'thick' sincerity accommodates the slipperiness of self-knowledge by allowing that sometimes my self-understanding is wrong, and my sincerity accordingly impoverished. Through the examples of Claudius and Forrest Gump, among others, we can see how sincerity and authenticity are separable and uncorrelated to other virtues as well.

My second task in this paper was to provide some analysis of the assumptions about selfhood at work in the usual cleavage between sincerity and authenticity. By incorporating the insight that the self is not a rigorously defined interior object, we can see that sincerity comes in degrees and that authenticity is related to sincerity insofar as behaviour - what we show others of 
ourselves - contributes directly to the content of our selves as well as to the impression we make. Nonetheless, even on dialogical and deflationary accounts of the self, the separation between self and other never totally disintegrates. Although my identity is being molded in a social context, I reserve the ability to express or withhold my beliefs about myself - whether they are 'accurate' or not - or even to adopt a shtick. A fuller account of authenticity is still needed, but even with a provisional understanding it can be observed that authenticity does not collapse wholly into sincerity or vice versa. There is always some space for choosing between sincerity and dissimulation. As such, the authenticity of the self-relation cannot necessarily determine the sincerity of the others-relation. 'To thine own self be true' might be sage advice, but if so, it is not on the basis of its instrumental relation to sincerity. ${ }^{31}$ 


\section{Notes}

1. There are alternate interpretations of Polonius's words: for instance, 'thou canst not then be false to any man' could be intended to mean 'you will be a loyal friend' or something to that effect. Being 'true to oneself' is not idiomatically parallel to 'being true to others.' The latter expression often pertains to norms of fidelity or emotional support rather than avoiding false representations of oneself.

2. See for example Adorno (1964).

3. As I show below, it is possible for the content of these enterprises to overlap.

4. It does, however, present other metaphysical challenges, some of which I explore below.

5. In the course of his argument 'desire' can at times be replaced with belief, motive, or action. Like Parfit, Frankfurt uses 'desire' broadly (Parfit 117).

6. 'Whichever of these first-order desires actually leads to action is, by virtue of that effectiveness, designated the will of the individual whose desire it is' (Frankfurt 1988: 163).

7. There are compelling reasons to regard this account with suspicion. David Velleman persuasively argues that a person who divorces herself from certain desires for the sake of identifying with others, as Frankfurt recommends, might be better described as mentally ill than as 'wholehearted' (Velleman 2006). This is a powerful objection to Frankfurt's prescription for achieving wholeheartedness, but we can still use the concept of wholeheartedness (perhaps arising accidentally) as an analog of authenticity without accepting the view that it is healthy or morally sound to divide oneself mentally in its pursuit.

8. I resist equating authenticity and wholeheartedness - as well as giving a statement of their similarities and differences - in part because they have different scopes. Wholeheartedness is a state, or a process, of reconciling one's motives at a given moment, whereas authenticity is a more complex, arguably lifelong, goal of being a certain type of person. Lacking the space in this paper to explore and defend a detailed account of authenticity, I appeal to wholeheartedness as an indicative but not exhaustive component of a complete account.

9. Although we are still in the process of exploring what is meant by the 'self,' I take the term 'selfknowledge' to be applicable here in a nominal sense. One can have knowledge (understanding) of his or her motives and desires, regardless of whether these belong to an entity we can identify by other characteristics - that is, regardless of whether there is a stable subject that owns the motives.

10. Ricoeur calls this 'narrative intelligence' (143 fn).

11. Even this might not result in something so lofty as 'self-knowledge,' but the aspiration and the effort are characteristic of authentic and wholehearted individuals. Note that self-knowledge can also be facilitated through interactions with others, and thus does not always chronologically precede sincerity.

12. I am using this loaded term in a strictly action-oriented sense, not in the manner used by phenomenologists or philosophers of mind.

13. This is not to say that others cannot influence such changes in direction. As I argue below, the view of an individual who makes choices about her identity in isolation from others is implausibly simplistic.

14. Notice that this illustrates the incongruence between wholeheartedness and morality.

15. This is the same constellation of traits in Molière's character Tartuffe, whom Trilling also cites as an example of self-truthfulness combined with external duplicity (16). Claudius and Tartuffe may not be truly authentic if we want to build morality into the definition of authenticity, but I leave this question aside for now.

16. One could just as easily identify the same unexpected combination of authenticity and insincerity in Hamlet. Hamlet deliberately presents himself as mad, which (at least initially) he is not, after taking a careful inventory of his motives and adopting a wholehearted strategy to achieve a certain aim.

17. As above, I am not suggesting that there is some objective truth about what or who a person really is, but I certainly think that it is possible for there to be a disparity between why we think we do something and why we actually do it. This discrepancy can be observed in retrospect or with the help of an insightful friend, for example. When we aver that an earlier belief about ourselves was mistaken, we appeal to wholeheartedness: the new belief resonates more fully through our infinite layers of desires and motives than did the earlier one. Hence we have a reason for declaring one state to be more authentic than the other.

18. Williams argues that the value of sincerity also implies the value of truth, i.e. that the sincere assertions be accurate as well (149).

19. Trilling also makes distinctions between types of sincerity, but his fault lines are national: 'In French literature sincerity consists in telling the truth about oneself to oneself and to others; by truth is meant a recognition of such of one's own traits or actions as are morally or socially discreditable and, in conventional course, concealed. English sincerity does not demand this confrontation of what is base or shameful in oneself. Not to know oneself in 
the French fashion and make public what one knows, but to be oneself, in action, in deeds . . this is what the English sincerity consists in' (58). On this definition, Gump's sincerity is more English than French.

20. As readers of an epistolary novel that contains no narrative outside the characters' letters to one another, we can no more verify Julie's sincerity to her correspondents than they can. This is an interesting feature of the relationship between sincerity and authenticity in first-person fiction: since there is no real person named Julie with a subjective perspective on her authenticity, we can only assess a character's authenticity from the same vantage point from which we usually assess sincerity, i.e. what the character tells us.

21. I am particularly influenced in this regard by Foucault (1988a, 1988b, 1997) and Ricoeur (1992).

22. Although her analysis in Gender Trouble focuses on questions of identity relating to sex, gender, and desire, her deflationary position is applicable to other areas of personal identity as well.

23. The term 'expression' is ambiguous. I take Butler to be referring to the possibility of sincerity simpliciter, i.e. making external what is felt or known internally, prior to being expressed. Taylor attributes to some Romantic thinkers what he calls 'expressivism,' which is slightly more complicated than what Butler means by 'expression' insofar as the medium helps to define the content of what is expressed. Eighteenth century expressivists would agree with Butler that identity is not entirely formed prior to being expressed (or per-formed) but disagree that nothing essential precedes that performance.

24. This is different from Butler's contention that identities are imposed, sometimes violently, by others. Instead, we are all simultaneously creators of identities and recipients of ideas and suggestions about our own identities.

25. This view is much closer to the Romantic notion of 'expressivism' (see note 23).

26. Trilling observes that role-playing was of particular concern to early modern audiences, in an era when new-found social mobility threatened to dislodge the established code by which one recognized a person's social station (16). This is of course less of a concern to us now.

27. If Tartuffe were suffering delusions that he was a priest, then his behaviour could be considered sincere. This would be an instance of 'thin sincerity,' since the content of his beliefs about himself would be false. He is not a priest in the way that society defines priesthood, and without which priesthood as such would cease to exist.

28. Whether Tartuffe is authentic is another question. The issue here would be whether pretending to be a priest (or otherwise duping a wealthy family to access their money) is the most consistent behaviour with his as yet undefined true self - whether he wants it wholeheartedly, etc. This is entirely possible, showing again that one may be authentic while being insincere.

29. In Sartre's vernacular, being-for-itself is always free, but in bad faith one attempts to achieve the necessary and simplistic being of being-in-itself. He explains: 'What I attempt to realize is a being-in-itself of the café waiter, as if it were not just in my power to confer their value and their urgency upon my duties and the rights of my position, as if it were not my free choice to get up each morning at five o'clock or to remain in bed, even though it meant getting fired (Sartre 103).'

30. Sartre's judgment that the waiter is in bad faith is derived from his ontological view of authenticity as willing one's radical freedom. For him, inauthenticity, or bad faith, constitutes a failure to recognize or embrace the true nature of one's being as being-for-itself. Insofar as the waiter is mistaken about the degree to which he is a waiter, by Sartre's criteria, we can say that his sincerity is at best thin: his self-knowledge is inaccurate, because he sees himself as being-in-itself rather than being-for-itself. If we reject Sartre's definition of waiterhood and consequently his assessment of the waiter's self-knowledge, this example is not a case of thin vs. thick sincerity, but rather of shtick.

31. A number of individuals provided valuable feedback on earlier versions of this paper. I would like to thank Christine Overall, Mark Kingwell, Lambert Zuidervaart, members of the Canadian Philosophical Association, and two anonymous reviewers for this journal. 


\section{References}

Adorno, Theodor W. The Jargon of Authenticity. 1964. Trans. Knut Tarnowski and Frederic Will. Evanston: Northwestern UP, 1973.

Butler, Judith. Gender Trouble: Feminism and the Subversion of Identity. New York: Routledge, 1999.

Foucault, Michel. Essential Works of Foucault 1954 - 1984, Vol. 1: Ethics, Subjectivity and Truth. Ed. Paul Rabinow. New York: New Press, 1997.

- - -. Technologies of the Self. Ed. Luther Martin, Huck Gutman, and Patrick Hutton. Amherst: U of Massachusetts P, 1988.

- - -. The Care of the Self: The History of Sexuality, Vol. 3. Trans. Robert Hurley. New York: Vintage, 1988.

Frankfurt, Harry. 'Identity and Wholeheartedness.' The Importance of What We Care About. Cambridge: Cambridge UP, 1988. 159-176.

- - -. $\quad$ On Truth. New York: Knopf, 2006.

Parfit, Derek. Reasons and Persons. Oxford: Clarendon, 1984.

Ricoeur, Paul. Oneself as Another. Chicago: U of Chicago P, 1992.

Rousseau, Jean-Jacques. The Collected Writings of Rousseau, Vol. 6: Julie, or the New Héloïse. Trans. Philip Stewart and Jean Vaché. Hanover: UP of New England, 1997.

Sartre, Jean-Paul. Being and Nothingness. 1943. Trans. Hazel Barnes. New York: Washington Square, 1984.

Shakespeare, William. Hamlet. Ed. G.R. Hibbard. Oxford: Oxford UP, 1987.

Taylor, Charles. Sources of the Self. Cambridge: Harvard UP, 1989.

Trilling, Lionel. Sincerity and Authenticity. Cambridge: Harvard UP, 1972. 
Velleman, J. David. 'Identification and Identity.' Self to Self: Selected Essays.

Cambridge: Cambridge UP, 2006. 330-360.

Williams, Bernard. Truth and Truthfulness: An Essay in Genealogy. Princeton: Princeton UP, 2002. 